\title{
The book that began invasion ecology
}

\section{Charles Elton's 50-year-old text founded a field and is now cited more than ever.}

\author{
The Ecology of Invasions by Animals and \\ Plants \\ by Charles S. Elton \\ Methuen: 1958. $181 \mathrm{pp}$.
}

\section{Anthony Ricciardi and Hugh J. Maclsaac}

Human activities have introduced alien animals, plants and microbes to all but the remotest regions of Earth. These biological invasions threaten ecosystems, economies and human health, and are the focus of a highly productive subdiscipline of ecology, the origin of which can be traced to a book that was published 50 years ago.

The Ecology of Invasions by Animals and Plants by British ecologist Charles S. Elton is, remarkably, not a scientific treatise or an academic text, but an expansion of a short series of BBC radio broadcasts aimed at the public. At the time, Elton was the most influential figure in animal ecology, having pioneered studies on population dynamics and food chains. He was particularly interested in what he called "ecological explosions" - enormous, uncontrolled increases in population.

Previously, ecologists had treated invasions as anomalies. Elton characterized them as being symptomatic of a process that could alter the biological landscape of the planet. "We are seeing one of the great historical convulsions of the world's fauna and flora," he wrote. In an effort to move the study of invasions beyond natural historical accounts, Elton produced testable generalizations drawing from disparate disciplines, including biogeography, epidemiology and human history. He also identified large-scale patterns, such as the higher number of invaders in temperate regions compared with tropical regions, and on islands versus mainland areas of equivalent size (both recently verified by statistical analyses).

Most importantly, Elton demonstrated the profound influence of human activities in reshaping species distributions. For example, decades before other scientists began to focus on the spread of invading alien aquatic species, Elton drew attention to the transport of organisms in ships' ballast tanks, the intercontinental movement of oysters and their associated flora and fauna, and the role of canals in linking regions formerly isolated from each other for millions of years.

Many of the concepts raised in The Ecology of Invasions by Animals and Plants have flourished into important research themes that continue to be vigorously debated. Most notable of these is the 'biotic resistance' hypothesis: that species-rich communities

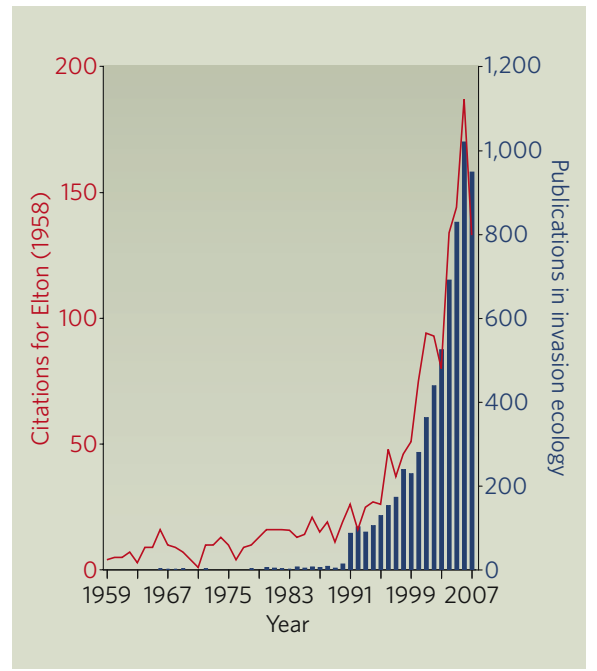

are more resistant to invasion. Elton proposed that diverse communities use resources more fully, leaving fewer niches for potential colonists to exploit. Recent studies have found that invaders in small, species-rich areas do indeed fare worse than those in areas of low biodiversity. But the pattern often reverses over large areas, apparently driven by external environmental conditions that affect native and alien species alike.

Elton also argued that complex food webs are likely to contain predators or parasites that can control invaders, whereas simpler food webs are more vulnerable to population explosions. As evidence, he pointed to the disproportionate numbers of invaders in environments such as remote islands and boreal forests, and those on cultivated land and in other environments that have been drastically simplified by human disturbance. These ideas have had a huge influence on subsequent ecological research into the link between a community's diversity and its stability. Elton further suggested that many species are invasive because they arrive in areas without their natural enemies, another controversial hypothesis that has generated many recent studies. His book is cited by more than $40 \%$ of published papers that address biotic resistance, enemy release or diversity-stability, according to Thomson Scientific's Web of Science.

Elton demonstrated the key role that some invasions have had in the reduction and extinction of native populations - an effect that became widely recognized only in the 1980s. "The eventual state of the biological world will become not more complex but simpler and poorer," he wrote. "Instead of six continental realms of life ... there will only be one world." This stark prediction may have inspired yet another current research theme: the consequences of the replacement of unique assemblages of plants and animals by widespread alien species that coexist with humans, such as rats, starlings and carp.

Half a century on, invasion ecology has progressed well-beyond the scope of Elton's book. Several topics that are now crucial to our current understanding were overlooked or only touched on by Elton. These include: the number of introductions or individuals a population requires to become established; the evolutionary effects of invasions; and interactions among alien species that enhance each other's success. Commerce in agriculture, aquaculture, ornamental plants and pets has opened up the world to thousands of potential invaders, often aided by rapid unregulated trade through the Internet. The release of genetically modified organisms has added another dimension. To try to predict invasions, researchers are examining traits that predispose species to interface with and survive transport by humans. Invasion ecology has had to embrace risk analysis, resource economics, computer modelling and molecular genetics.

Yet Elton's influence on the field continues to grow. The citation rate of his book (pictured, red line) has risen dramatically since the early 1990s after a time lag of some 30 years (a rise that, incidentally, could be compared to the exponential population explosion of an alien species). Why did the surge in journal publications in this discipline take so long to occur? Perhaps a few devastating and well-documented invasions lit the fuse that Elton laid down years before - such as those involving the Nile perch in Lake Victoria, the 'killer alga' Caulerpa taxifolia in the Mediterranean and the zebra mussel in North America. Perhaps the interest in biodiversity in the 1980s - the 'conservation of variety' that Elton stridently advocated - brought broader recognition to invasions as a major cause of extinction.

Or perhaps the delay illustrates how far ahead of its time The Ecology of Invasions by Animals and Plants was. Elton died in 1991, just as the field he founded began to flourish (pictured, blue bars). His book sounded an early warning that, having gone largely unheeded for three decades, has become a clarion call that resonates in the work of invasion ecologists worldwide.

Anthony Ricciardi is an associate professor at the Redpath Museum, McGill University, Montreal, Quebec, Canada H3A 2K6. Hugh J. Maclsaac is a professor at the Great Lakes Institute for Environmental Research, University of Windsor, Ontario, Canada N9B 3P4. 